\title{
O uso da técnica de role-playing como sensibilização dos alunos de Medicina para o exame ginecológico
}

\author{
The use of role-playing as a sensitization \\ technique for medical students during \\ gynecological examination
}

\author{
Julio Cesar Soares Aragão ${ }^{I}$ \\ Camila Oliveira da Silveira ${ }^{\mathrm{I}}$ \\ Milena de Mattos Hungria ${ }^{\mathrm{I}}$ \\ Mirella Pereira de Oliveira ${ }^{\mathrm{I}}$
}

\section{PALAVRAS-CHAVE \\ - Desempenho de Papéis. \\ - Estudantes de medicina. \\ - Ginecologia.}

Recebido em: 28/02/2008

Reencaminhado em: 10/04/2008

Aprovado em: 13/05/2008

\section{RES U M O}

Exames ginecológicos são especialmente sensíveis tanto para os estudantes inexperientes quanto para a mulher que está sendo examinada. O uso do role-playing ou troca de papéis tem sido cada vez mais reconhecido como forma de aprendizagem das habilidades de comunicação e tem se tornado particularmente importante. Com o intuito de analisar o impacto da troca de papéis nos acadêmicos de Medicina admitidos no módulo de Ginecologia e Obstetrícia do internato, foram realizadas simulações de exame ginecológico durante o ambulatório de ginecologia, com o consentimento dos alunos. A dinâmica foi incorporada e interpretada pelos participantes de modo pleno, demonstrando que as soluções para as questões abordadas podem ser encontradas no intimo de cada aluno que passa por uma situação de inversão de papéis com sua paciente. Se for possível trazer a experiência do role-playing ou troca de papéis para o ensino médico e para a vida profissional, certamente nos colocaremos no lugar de cada paciente na hora do exame, o que fará da dinâmica realizada um instrumento para a humanização no ensino da ginecologia.

\section{A B S T R A C T}

Gynecological examinations are especially sensitive, both for the inexperienced student and the patient. In order to analyze the impact of role-playing on medical students beginning their ob-gyn rotation in internship, simulated gynecological examinations were performed in the gynecology outpatient clinic, with the students' consent. The dynamic was fully incorporated and interpreted by the students, demonstrating that they had the inner capacity to find solutions to the issues that arose when they traded places with the patients. If it were possible to use role-playing in both medical education as a whole and future medical practice, we would certainly put ourselves in the patient's place when we perform an examination, thus making the technique a tool for humanizing the teaching of gynecology. 


\section{INTRODUÇÃO}

A despeito de toda tecnologia incorporada pela prática médica nas últimas décadas, o exame físico permanece como pedra angular do diagnóstico e da relação médico-paciente, e seu aprendizado é de suma importância na educação médica ${ }^{1}$.

Os exames ginecológicos são especialmente sensíveis tanto para os estudantes inexperientes quanto para a mulher que está sendo examinada ${ }^{2}$. A partir da necessidade de aprimorar a qualidade do atendimento ginecológico e obstétrico nos âmbitos interpessoal e técnico, algumas práticas estão sendo adotadas para complementar o ensino tradicional.

Em estudo para avaliar a percepção dos estudantes de Medicina sobre suas habilidades psicomotoras e atitudes diante dos diferentes métodos de ensino da prática ginecológica, $\mathrm{Abraham}^{3}$ observou que a primeira preferência dos alunos avaliados era aprender o exame pélvico sob a supervisão de um médico capacitado.

Pela grande necessidade em rever e avaliar criticamente a educação médica, o uso do role-playing ou troca de papéis tem sido cada vez mais reconhecido como forma de aprendizagem e de comunicação e tem se tornado particularmente importante, porém difícil de aprender na prática ${ }^{4}$. Segundo Carr e Carmody $^{5}$, por meio de um estudo feito por dois anos com estudantes de Medicina e mulheres da comunidade invertendo seus papéis, constatou-se aumento da confiança e redução da ansiedade na condução dos exames pélvicos sem supervisão. Entre $92 \%$ e $100 \%$ dos acadêmicos e mulheres da comunidade concordaram em que esse programa ajudou a preparar melhor os estudantes para a vida clínica.

O presente trabalho tem o objetivo de avaliar as percepções dos alunos ao serem submetidos a uma simulação de exame físico ginecológico e as possíveis mudanças de comportamento que estas vivências podem propiciar ao discente.

\section{MÉTODO}

\section{Role-playing}

Com o intuito de analisar o impacto da troca de papéis nos 60 acadêmicos de Medicina admitidos no módulo de Ginecologia e Obstetrícia do internato (décimo primeiro período), foram realizadas simulações de exame ginecológico durante o ambulatório de ginecologia. As simulações foram realizadas em grupos de 15 alunos, sendo repetidas em quatro grupos diferentes. A simulação ocorreu na policlínica onde os alunos comparecem ao ambulatório do internato, sendo, assim, o mesmo cenário de suas práticas diárias. O consentimento informado foi obtido dos discentes, e a participação na dinâmica não foi obrigatória ou compulsória. O professor envolvido nesta atividade não participa de atividades de avaliação (provas, conceitos, etc.) e, portanto, os alu- nos não teriam motivos para se sentirem coagidos a participar da atividade. O projeto foi aprovado pelo Comitê de Ética em Pesquisa da instituição (Registro Sipar - Ministério da Saúde: 25.000.158.694/2007-89).

Os discentes do sexo masculino de cada grupo foram solicitados a vestir a camisola de exame por cima de suas roupas e a deitar na mesa em posição ginecológica. O espéculo vaginal foi passado entre a mesa e o dorso dos alunos por uma aluna, enquanto o restante do grupo de aula prática assistia à simulação. O professor encarregado da dinâmica orientava a aluna quanto a possíveis patologias existentes e corrigia a técnica durante o exame, simulando o exame real em paciente do ambulatório.

\section{Grupo focal}

Após todos os alunos do sexo masculino participarem da dinâmica, foi realizada uma discussão em grupo focal sobre a experiência de cada aluno, entre participantes, examinadoras e platéia, onde as vivências da simulação eram avaliadas. Estas discussões eram realizadas pelo mesmo professor e não tinham duração determinada. O professor começava a discussão pedindo que os alunos do sexo masculino relatassem a vivência da dinâmica, passando em seguida a palavra às alunas. As falas dos estudantes foram gravadas e depois transcritas e revisadas.

\section{Análise}

A análise utilizada no presente estudo é qualitativa, com base metodológica calcada na fenomenologia proposta por Heiddeger $^{6}$. Esta abordagem propõe um distanciamento entre o pesquisador e o fato, abandonando preconceitos e posições prévias, possibilitando, assim, uma análise das vivências relatadas na forma de fenômeno ${ }^{7}$. O conteúdo dos discursos transcritos foi agrupado em categorias, como proposto por Minayo e Sanches ${ }^{8}$, que foram posteriormente agrupadas e categorizadas para discussão ${ }^{9}$.

\section{RESULTADOS}

A análise dos discursos dos estudantes nos possibilitou destacar dois temas principais: o constrangimento do exame especular e o ensino da prática ginecológica.

O constrangimento foi abordado de diferentes formas, sendo relacionado principalmente à vergonha de estar sendo submetido ao exame:

Eu me senti muito constrangido ao ser examinado[...]fiquei com muita vergonha, por isso ofereci tanta resistência (aluno 4).

Também foi abordada a posição da cabeça durante o exame, refletindo o sentimento de vulnerabilidade: 
Eu fiquei constrangido pela posição da cabeça que você não vê ninguém, não consegue olhar pra ninguém e na hora que a turma vai olhar e você naquela posição, não sabe pra onde a pessoa tá olhando, se tá comentando. Isso pra mim foi o maior constrangimento (aluno 7).

A posição ginecológica foi tema de várias observações; entre elas, uma das examinadoras ressalta:

Pude observar que eles ficaram muito constrangidos ao ficarem na posição ginecológica e ao se sentirem tão expostos. Achei muito importante explicar para eles o que estava acontecendo durante o exame e notei que com isso a tensão dos meninos diminuía (aluna 1).

A seguir, os próprios alunos propuseram soluções para amenizar o desconforto da paciente que se submete ao exame ginecológico, salientando situações referentes a sua própria experiência:

Achei uma situação muito complicada e pude observar que o paciente tem que ter uma confiança muito grande no médico. É muito importante o médico ir explicando passo a passo o que está fazendo com o paciente durante o exame, para o tranquilizar. Acho que seria bom se o médico explicasse para o paciente o que é um espéculo, mostrasse o espéculo para ele (sic), para depois fazer o exame especular (aluno 4).

É possível observar o profundo envolvimento deste aluno na situação vivenciada, a ponto de considerar "o paciente" como sendo do sexo masculino em seu discurso.

Quando o assunto é confiança, podemos colocar em discussão o ensino da ginecologia durante a graduação, nos indagando de que maneira a experiência do examinador está relacionada com a confiança que é passada à paciente.

Pude observar nas aulas práticas de ginecologia que os alunos muitas vezes ficam com medo de examinar as pacientes. Eles ficam tão envergonhados quanto a própria paciente (aluna 8).

Esta fala explicita como a inexperiência pode levar à insegurança, dificultando ao aluno inspirar confiança nas pacientes, conforme assinalam Abraham et al. ${ }^{10}$. O constrangimento, dessa forma, é analisado por um outro ângulo, de um outro ponto de vista: a visão do aluno, que se vê diante de uma difícil situação: o exame ginecológico, além de ser incômodo para a paciente, também é incômodo para o médico (aluno 12).

[...] dentro de uma escola de Medicina a situação é mais complexa ainda, porque a paciente sabe que, antes de ser examinada pelo médico, vai ser examinada por um aluno, e, às vezes, até por mais de um estudante, e essa paciente vai ter que falar sobre assuntos delicados, como, por exemplo, sexualidade e atitudes corporais (aluno 4).

No ensino médico existem fatores complicadores para a paciente, como a existência de uma "platéia" assistindo e o fato de um aluno, antes mesmo do professor, realizar (ou tentar realizar) este exame.

\section{CONCLUSÕES}

A técnica de role-playing pode ser usada para desenvolver as habilidades de comunicação propostas pelas Diretrizes Curriculares Nacionais do Curso de Graduação em Medicina ${ }^{11}$, propiciando também um ambiente de aprendizagem centrado no estudante com metodologia ativa ${ }^{10}$.

A dinâmica foi incorporada e interpretada pelos participantes de modo pleno, demonstrando que as soluções para as questões abordadas podem ser encontradas no íntimo de cada aluno que passa por uma situação de inversão de papéis com sua paciente. Essa reflexão é peça-chave para assimilação de conteúdos conceituais e atitudinais relevantes para a práxis médica, como observado por Henderson e Johnson ${ }^{12}$ em relação a estudantes de Medicina britânicos em 2002. Em vários momentos, pôde ser observado como é importante a confiança da paciente no médico examinador, a relevância em se explicar passo a passo o que está sendo feito e narrar o que está sendo visto, de modo que a paciente fique a par do que está acontecendo fora do seu campo visual. As palavras de um dos alunos sintetizam a discussão desenvolvida:

Pude observar que a posição é incômoda, que é uma situação muito constrangedora. Acho que, apesar de termos aula num ambulatório para acadêmicos, é muito importante aprendermos a respeitar as pacientes, pois achei muito complicado ser examinado com várias pessoas em volta (aluno 17).

Assim, baseamos nossa conclusão na necessidade de respeito, que é indispensável à realização de qualquer ato médico. Se 
for possível trazer a experiência do role-playing ou troca de papéis para o ensino médico e para a vida profissional, certamente nos colocaremos no lugar de cada paciente na hora do exame, o que fará da dinâmica realizada um instrumento de grande valor para a humanização no ensino da ginecologia e diminuição do constrangimento vivenciado por pacientes durante o exame ginecológico em ambientes de ensino ou em qualquer atendimento ginecológico ${ }^{13}$.

Ensinar a base cognitiva do profissionalismo e promover oportunidades para internalizar seus valores e comportamentos são o ponto de intersecção do ensinar o profissionalismo em todos os seus níveis. Em consonância com o relatado por Cruess et al. ${ }^{14}$, a teoria pode variar com o tipo de escola, mas os princípios do profissionalismo se mantêm constantes.

\section{REFERÊNCIAS}

1. Mondredinho AR, Silva RM. Percepção dos pacientes sobre a sua participação como instrumento de aprendizado nas aulas práticas de semiologia. Arq. Catarin. Méd. 2006;35(3):35-41.

2. Wånggren K, Pettersson G, Csemiczky G, Gemzell-Danielsson K. Teaching medical students gynaecological examination using professional patients-evaluation of students' skills and feelings Med Teach. 2005;27(2):130-135.

3. Abraham S. Vaginal and speculum examination in medical curricula. Aust N Z J Obstet Gynaecol. 1995;35(1):56-60.

4. Coonar AS, Dooley M, Daniels M, Taylor RW. The use of role-play in teaching medical students obstetrics and gynaecology. Med Teach. 1991;13(1):49-53.

5. Carr SE, Carmody D. Outcomes of teaching medical students core skills for women's health: the pelvic examination educational program. Am J Obstet Gynecol. 2004;190(5):1382-1387.

6. Heidegger M. Ser e tempo. 3 ed. Trad. Márcia de Sá Cavalcante. Petrópolis: Vozes; 1993. 325 p.

7. Lopes RLM, Souza IEO. A fenomenologia como abordagem metodológica: compartilhando a experiência de mu- lheres que buscam a prevenção do câncer cérvico-uterino. Rev.latino-am.enfermagem, 1997;5(3):5-11.

8. Minayo MCS, Sanches O. Quantitativo-Qualitativo: Oposição ou Complementaridade? Cad. Saúde Públ. 1993;9(3):239-262.

9. Minayo MCS. O desafio do conhecimento: pesquisa qualitativa em saúde. 7 ed. São Paulo:[S.n.]; 2006. 269p.

10. Abraham S, Chapman M, Taylor A, McBride A, Boyd C. Anxiety and feelings of medical students conducting their first gynecological examination. J Psychosom Obstet Gynaecol. 2003; 24(1):39-44.

11. Brasil. Ministério da Educação. Conselho Nacional de Educação. Câmara de Educação Superior. Diretrizes curriculares nacionais do curso de graduação em Medicina. Resolução Cne/Ces № 4, de 07 de novembro de 2001; Diário Oficial da União. Brasília, 9 nov. 2001; Seção 1, p.38.

12. Henderson $\mathrm{P}$, Johnson MH. Assisting medical students to conduct empathic conversations with patients from a sexual medicine clinic. Sex Transm Infect. 2002;78(4):246-249.

13. Lopes RLM. A mulher vivenciando o exame ginecológico na prevenção do câncer cérvico-uterino Rev. Enferm. 1994;2(2):165-170.

14. Cruess R, Mcilroy JH, Cruess S, Ginsburg S, Steinert Y. The Professionalism Mini-evaluation Exercise: a preliminary investigation. Acad Med. 2006; 81(10 Suppl):S74-8.

\section{CONFLITO DE INTERESSES}

Declarou não haver

\section{ENDEREÇO PARA CORRESPONDÊNCIA}

Julio Cesar Soares Aragão

Rua 156, 380 - sala 208

Laranjal

CEP. 27255-08 - Volta Redonda - RJ

E-mail julio.aragao@foa.org.br 